\title{
Job Satisfaction and Faculty Turnover Intentions: A Case of Pakistani Universities
}

\author{
Sadaf Zahra ${ }^{1}$, Amna Irum ${ }^{1}$, SaadMir $^{1}$, Anwar Chishti $^{2}$ \\ ${ }^{I}$ (Army Public College of Management Sciences, Ordnance Road, Rawalpindi, Pakistan) \\ ${ }_{2}^{2}$ (Muhammad Ali Jinnah University, Islamabad, Pakistan)
}

\begin{abstract}
Retaining faculty members has been a problem in many universities for decades. When competent teachers quit, they depart with critical knowledge and experience that are essential for maintaininga competitive advantage. The aim of this study was to measure the impact of four facets of job satisfaction on turnover intentions of faculty members of different universities of Rawalpindi/Islamabad. A 16-item, selfadministered questionnaire was used to gather data on independent and dependent variables. In questionnaire, researchers used 5 point Likert scale for variables to measure respondent's possible responses. 110 questionnaires were completed and returned back. Pearson Correlation and Multiple Regression tests were used to test the hypothesis. The results showed that the three facets of job satisfaction i.e. remuneration, supervisory support and work life policies have significant and negative relationship with turnover intentions while recognition has insignificant relationship with turnover intentions and this relationship did not support the researchers' prediction. Results have been discussed andrecommendations have been made for universities' administrations.
\end{abstract}

Keywords - Employee Retention, Faculty Members, Job Satisfaction, Pakistani Universities, Turnover Intentions.

\section{Introduction}

The question of employee turnover has come to gain greater attention especially in this new century. Organizations all over the world, in various industries, have faced this problem at some stages of their evolution. Companies now take a deep interest in their employee turnover rate because it is a costly part of doing business. In order for an organization to be successful, they must continuously ensure the satisfaction of their employees. Volatile economic conditions, highly competitive recruitment practices and a diminishing pool of skilled candidates create further problems in the process of retention [1].

In 1980, there were nineteen universities and two degree awarding institutes in Pakistan. Today, there are ninety universities and twenty seven degree awarding institutions in the country. This phenomenal change has been caused due to regulatory and statutory changes at the Higher Education Commission (HEC) level. Along with the increase in number there has been a major change in the nature of the business of education. The education has been commercialized to an extent. The single most important factor in the increase of institutions and universities is due to the increase in the number of projected students. This paradigm shift has resulted in high turnover among teachers as many opportunities have become available to them. They now, can switch jobs and have the choices to select or reject institutions on the basis of factors they consider most important to their jobs.

Most of the universities of Pakistan are particularly affected by the problem of turnover as there is growing pressure on these universities to produce graduates in order to meet the needs of the country's dynamically changing business environment. Also, there is limited skilled faculty available. Universities, therefore, have no choice but to accommodate these changes and address the issue of turnover. This study will, thus, explore the nature of turnover, to develop a better understanding of the underlying issues of turnover and serve as a guide for university administrators to address this problem.

Retention of employees has been termed as one of the most significant challenges of the 21 st century [2]. Studies have differentiated between actual turnover and turnover intent, with more focus on turnover intent. Actual turnover is more difficult to predict because it involves the study of those individuals who have left their organizations. It is difficult to trace such individuals and to retrieve data from them. However, turnover intent is termed to be the most predictive sign of actual turnover in an organization [3].

Over the past few decades, there have been a large number of researches done on job satisfaction, and the antecedents of turnover. However, there are very few studies that have concentrated on finding out the path that leads from job satisfaction to turnover intentions, which in turn leads to actual employee turnover. [4] Suggested that there are a number of cognitive and behavioral phenomena that occur between the emotional experience of job satisfaction and the action of quitting. Recent models suggest that a number of organizational factors affect a person's job satisfaction and commitment, which influence the intentions to quit, and initiate the 
process of looking for another job and then finally quitting in actual [5]. In comparison, one such model that has received significant attention and described this relationship, is that job dissatisfaction arouses thoughts of quitting among employees which in turn lead to looking for another job, evaluating the findings and then intentions of quitting and finally to the action of quitting [4].

The most commonly studied antecedents to turnover identified in literature are job satisfaction, intention to leave, organizational commitment, job search behavior, and economic factors [6]. There are a variety of factors that can influence a person's level of job satisfaction; some of these factors include the level of pay and benefits, the perceived fairness of promotion system within a company, the quality of working conditions, leadership and social relationships, and the job itself (the variety of tasks involved, the interest and challenge the job generates, and the clarity of the job description and requirements).

Other researches have claimed that quitting intentions are a stronger predictor of turnover [3]. The decision of voluntarily quitting an organization is based on factors that may be personal or work related or even related to economic factors [7]. [8] Have concluded job satisfaction as a precursor of turnover and have suggested that turnover and job satisfaction may be influenced by individual demographic factors such as age, tenure, gender etc.

Companies take a deep interest in their employees' turnover rate because it is a costly part of doing business. When a company requires replacing a worker, the company incurs direct and indirect expenses. These expenses include the cost of advertising, headhunting fees, human resource costs, loss of productivity, training for new employees and customer retention. A large number of studies have suggested an inverse relationship between job satisfaction and intentions to quit; however, there are gaps in the available literature. Moreover, there are a number of gaps between the relationship of voluntary employee turnover and employee turnover intentions. Unfortunately, there has been almost no research conducted in Pakistan on issues relating to faculty job satisfaction and turnover intentions. Only one slightly relevant study was found which determined the relationship between selected personal characteristics, facets of job satisfaction, the two dimensions of organizational justice (distributive and procedural justice) and organizational commitment of university teachers in Pakistan [9]. The findings proved the relationship and showed a negative correlation between organizational commitment and turnover.

This study is inspired by the complex and multifaceted nature of turnover in the education industry in Pakistan, particularly in relation to job satisfaction and turnover intentions of the faculty members of universities in the cities of Rawalpindi and Islamabad. This study could help administrators and educators to understand the evolving perceptions of faculty job satisfaction and turnover intentions and improve the work related factors that can lead to more committed, satisfied and empowered faculty members.

\subsection{Problem statement}

Employee retention is becoming an important issue for organizations world over. The costs of employee turnover and replacement are huge and becoming less bearable in the fast paced economy. The higher educational industry, especially universities of Pakistan are facing the problem of high turnover as more choices have become available to a limited pool of faculty. Fewer studies have examined the effect of job satisfaction on turnover intentions, especially in the higher education sector. Almost no studies have been carried out on faculty job satisfaction and turnover intentions in universities of Pakistan.

Preliminary findings from other industries have proved a negative relationship between job satisfaction and turnover intentions. However, without further investigation, the same cannot be claimed for the education industry of Pakistan. This study will explore the relationship between factors of job satisfaction and turnover intentions.

Hence our research question becomesas:what is the relationship between factors of job satisfaction and turnover intentions?

\subsection{Objectives of the Research}

The objectives of this research are:

- To study the relationship of turnover intentions with the job satisfaction factors that are remuneration, work life policies, recognition, and supervisory support.

- To disclose the impact of these factors on turnover intentions among faculty members of universities of Pakistan.

- To recommend solutions to the adverse effects of turnover.

\subsection{Significance of Study}

This study will contribute to the literature on defined factors and turnover intentions in many ways.

- It will use a survey to better understand the turnover intentions among faculty members of universities in the cities of Rawalpindi and Islamabad. 
- After doing survey, it will give a fair idea about the problem of voluntary turnover within different universities.

- The relationshipof both these antecedents of turnover will be examined to reach any conclusions about how strongly the two factors are related. This study will provide a basis to make amendments to improve the working conditions of faculty in order to retain them.

- The result of the study can be extrapolated across the higher education sector in the rest of the areas in Pakistan and quality standards of education can therefore be raised by having satisfied and committed faculty.

\section{Literature Review}

Turnover becomes a serious but intractable issue. Unfortunately, despite employee turnover being such a serious problem in Asia, there is a lack of studies investigating it; in particular studies using a comprehensive set of variables are rare [10]. Organizational turnover occurs when members of the organization leave and are replaced by new personnel [11]. High turnover is found to be the major source of poor morale in many organizations [10]. Retention has become the greatest challenge for organizations to deal with in today's world. Retention becomes a potential problem when employees leave their jobs voluntarily [2].

Decision to quit is not usually made lightly but is instead the result of a carefully thought process [11]. In addition turnover often causes disruptions for existing members of organization, it may result in delays on important projects and it can cause problems when workers who quit are members of any team. Structure and culture are also affected by turnover.

[5]Define, Actual turnover is directly influenced by only one factor, turnover intentions. Turnover intention is one step removed from actual turnover [10].Behavioral intentions are a stronger predictor of employee turnover than job satisfaction. It appears that intentions are an important intermediate linkage between satisfaction, commitment, involvement and turnover [12].

[13] Has suggested that an employee who wants to quit his job tries to separate himself psychologically from that organization. An employee's attitude towards his job plays a vital role in determining his/her intention to leave, and these intentions actually indicate if an employee will actually leave the organization. He suggested that employee attitude surveys must be carried out periodically in order to measure employee job satisfaction, work related problems and intentions to leave so that proactive steps towards improvement can be taken by the employers.

Auditors who perceive that their workloads are reasonable and are balanced usually have lower intention to leave the current accounting firm [14]. Satisfaction with future career, company identity and financial rewards significantly affect turnover intentions. The higher, the satisfaction with any of these variables, the lower the turnover intentions [15]. [3]Conducted research about turnover and included a unified model that job dissatisfaction leads to job search behavior which leads to intentions of quitting or staying with the organization. Eventually, the person either actually quits or stays with the present organization.

An early study conducted by [16] concluded that the turnover is the result of a person's perceptions about desire to leave the organization and the ease of movement from one organization to the other. The "desire to leave the organization" was later equated with "job satisfaction" [17] and the "ease of movement" was equated with "perceived job alternatives" [6].

[4] concluded in his first research that four steps lead to turnover: (a) job dissatisfaction initiates thoughts of quitting, which leads to (b) evaluation of searching for a new job, which results in (c) intention to search and eventually, (d) actual job search behaviors. This could lead to (e) an analysis of alternative job opportunities, which could lead to (f) intentions to quit and then (g) action of quitting. He tried to explain this void between job satisfaction and turnover and suggested that there are a number of intermediate steps between the two, for example, intention to leave was more strongly related to turnover and is termed to be an intermediary in the process of job dissatisfaction and turnover.

[18] elaborated that turnover both real and contemplate, is an issue of importance in the life of the academy. People leave the faculty for a variety of reasons including retirement, accepting other faculty positions and moving into administrative positions. Each institution has its own "normal" turnover rate that is influenced by many factors. A college with an aging faculty will likely lose more to retirement than an institution with a younger faculty profile. A university in a metropolitan area may have more success in retaining faculty members because of social and cultural opportunities. Surprisingly, the rate of faculty leaving for retirement is generally a diminishing percentage of the total faculty who leave. This phenomenon should be monitored and possibly calls for more detailed analysis. As can be expected, faculty members at the assistant professor rank continue to show the greatest turnover rates in most units.

Collegial relations predict rather strongly intention to leave the university. The staff's relations to their colleagues can be a factor pushing them away from their institution. A variety of intrinsic and extrinsic motivators influence staff members while they are considering a future job [19].[20]found out that professors 
give great importance to their work because it gives them a chance to grow and develop their own abilities. [21]Found that interpersonal relationships and contacts are likely to affect the satisfaction level of professors.

\subsection{Hypothesis formulation}

$\mathrm{H}_{1}$ : there is a significant and negative impact of high remuneration on turnover intentions.

$\mathrm{H}_{2}$ : there is a significant and negative impact of recognition on turnover intentions.

$\mathrm{H}_{3}$ : there is a significant and negative impact of supervisory support on turnover intentions.

$\mathrm{H}_{4}$ : there is a significant and negative impact of work life policies on turnover intentions.

\subsection{Theoretical framework}

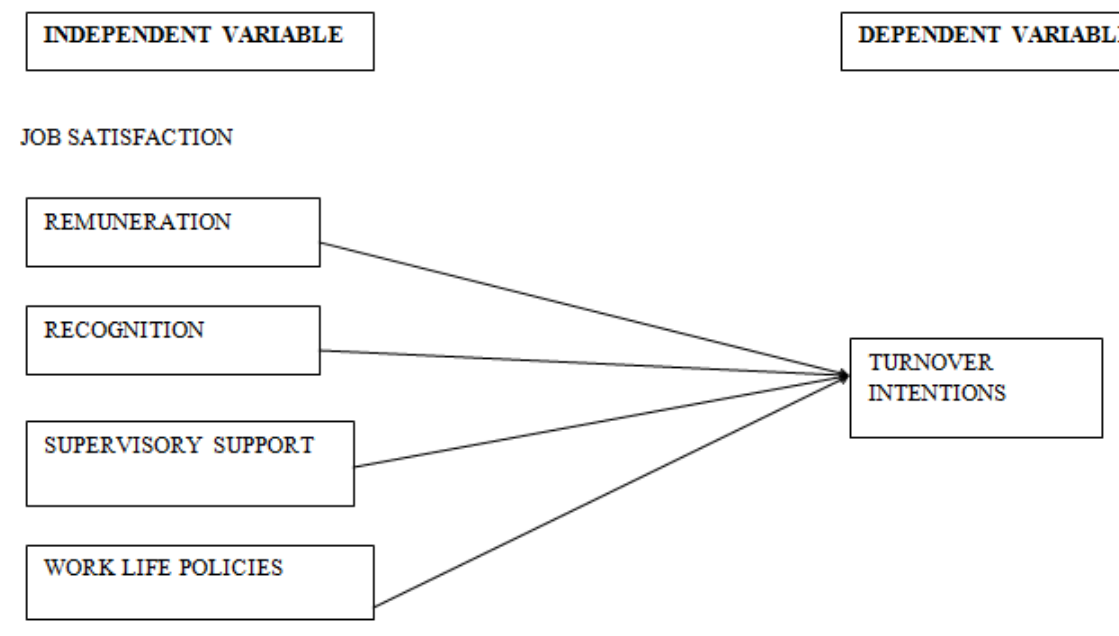

\section{Methodology}

This field study examined the impact of four facets of job satisfaction on turnover intentions among faculty of universities of Rawalpindi/Islamabad. A 16-item, self-administered questionnaire was used to gather data on independent and dependent variables. In our questionnaire we used 5 point Likert scale for variables to measure respondent's possible responses from $1=$ strongly disagree to $5=$ strongly agree.

We adopted the questionnaire used by [8] to measure job satisfaction variable. And to measure turnover intentions variable, we adopted questionnaire used by [9]. Recognition was measured using three items scale. The value of Cronbach's alpha for this scale was 0.89 . Work life policies variable was measured using four items. The value of Cronbach's alpha for this scale was 0.77 . Remuneration was measured using three items. The value of Cronbach's alpha for this scale was 0.71 . Supervisory support was measured using three items. The value of Cronbach's alpha for this scale was 0.92 . Turnover intentions variable was measured using three items and the value of Cronbach's alpha for this scale was 0.89 .

A printed questionnaire was distributed to 150faculty members working in Rawalpindi/ Islamabad universities.Faculty members were randomly selected. However 110 filled questionnaires were received backwhich indicates $73.3 \%$ response rate.

Data was then analyzed and hypotheses were tested using correlation and regression analysis. The Statistical Package for Social Sciences (SPSS) is used for data analysis. A co-relational and regression analysis will be used to assess the magnitude or intensity, and direction of the relationship between turnover intentions and the defined variables (factors of job satisfaction).

\subsection{Demographics}

\section{Results And Discussion} job rank is as follows:

Demographic composition of the sample in terms of gender, age, total years of teaching experience and

We found that 71 respondents were male and 39 respondents were female which describes percentage as $64.5 \%$ and $35.5 \%$ respectively. 78 respondents were in the age group of $25-35$ having $70.9 \%, 19$ respondents were in the age group of $36-45$ having $17.2 \%, 10$ respondents were in the age group of $46-55$ having $9.2 \%$ and 3 respondents were more than 55 years old having $2.7 \%$. The maximum respondents were between $25-35(71 \%)$, it shows that young people are more in teaching job. Response of teachers having teaching experience between $1-3$ years is $35 \%$ and less than 1year is $32 \%$ and teaching experience between $4-7$ years and more than that are very low. It depicts that after 2-3 years people tend to change their jobs. Response of $74 \%$ of teachers has job rank as lecturer, $17 \%$ teachers has job rank as assistant professor and only $8 \%$ are professors and it represents 
that teachers switch jobs very early and it can also be a reason that teachers are reluctant to higher studies. However demographic data has not been used in the analysis of the study.

\subsection{Correlation}

Hypothesis 1, 2, 3 and 4 were tested against correlation using Pearson correlational coefficient.

Results provided in Table 1 show that remuneration is significantly and negatively correlated with turnover intentions. The hypothesis $\mathrm{H}_{1}$ proposed that high remuneration correlates significantly and negatively with turnover intentions. This prediction is supported. High pay is negatively related to turnover intentions $(r=-$ 0.31 ) and this relationship is significant with $\mathrm{p}$ value 0.001 .This supports previous findings suggested by [10]that Satisfaction with pay is negatively associated with turnover intentions. Results from the present study suggest that employees' fair and competitive pay negatively relates to his intentions of turnover. This research indicated that an employee is more loyal with his job and very much satisfied when he receives high remuneration.

Table 1: Mean and Correlation

\begin{tabular}{|c|c|c|c|c|c|c|c|}
\hline Variables & $\mathrm{M}$ & & REC & WLP & RM & SS & TI \\
\hline REC & 2.55 & $\begin{array}{l}\mathrm{r} \\
\text { sig.(2- } \\
\text { tailed) } \\
\mathrm{N}\end{array}$ & 110 & $\begin{array}{l}0.02 \\
0.040 \\
110\end{array}$ & $\begin{array}{l}0.09 \\
0.000^{* *} \\
110\end{array}$ & $\begin{array}{l}0.04 \\
0.000^{* *} \\
110\end{array}$ & $\begin{array}{l}-0.10 \\
0.29 \\
110\end{array}$ \\
\hline WLP & 3.16 & $\begin{array}{l}\mathrm{r} \\
\text { sig.(2- } \\
\text { tailed) } \\
\mathrm{N}\end{array}$ & $\begin{array}{l}0.02 \\
0.040 \\
\\
110\end{array}$ & 110 & $\begin{array}{l}-0.11 \\
0.031 \\
\\
110\end{array}$ & $\begin{array}{l}-0.03 \\
0.001 \\
\\
110\end{array}$ & $\begin{array}{l}-0.41 \\
0.000^{\text {** }} \\
110\end{array}$ \\
\hline RM & 2.49 & $\begin{array}{l}\mathrm{r} \\
\text { sig.(2- } \\
\text { tailed) } \\
\mathrm{N}\end{array}$ & $\begin{array}{l}0.09 \\
0.000^{* * *} \\
110\end{array}$ & $\begin{array}{l}-0.11 \\
0.031 \\
\\
110\end{array}$ & 110 & $\begin{array}{l}0.23 \\
0.000^{* *} \\
110\end{array}$ & $\begin{array}{l}-0.31 \\
0.001 \\
110\end{array}$ \\
\hline SS & 2.35 & $\begin{array}{l}\mathrm{r} \\
\text { sig. }(2- \\
\text { tailed) } \\
\mathrm{N}\end{array}$ & $\begin{array}{l}0.04 \\
0.000^{* *} \\
110\end{array}$ & $\begin{array}{l}-0.03 \\
0.001 \\
110\end{array}$ & $\begin{array}{l}0.23 \\
0.000^{* *} \\
110\end{array}$ & 1 & $\begin{array}{l}-0.21 \\
0.02 \\
\\
110\end{array}$ \\
\hline TI & 3.44 & $\begin{array}{l}\mathrm{r} \\
\text { sig.(2- } \\
\text { tailed) } \\
\mathrm{N}\end{array}$ & $\begin{array}{l}-0.10 \\
0.29 \\
110\end{array}$ & $\begin{array}{l}-0.41 \\
0.000^{* *} \\
110\end{array}$ & $\begin{array}{l}-0.31 \\
0.001 \\
110\end{array}$ & $\begin{array}{l}-0.21 \\
0.02 \\
\\
110\end{array}$ & 110 \\
\hline
\end{tabular}

$P<0.01^{*}$

$R E C=$ Recognition, $W L P=$ Work life policies, $R M=$ Remuneration, $S S=$ Supervisory Support, $T I=$ Turnover intentions

Results in Table 1 show negative relationship between recognition and turnover intentions $(r=-0.10)$ but this relationship is not statistically significant with $\mathrm{p}$ value $0.29 . \mathrm{H}_{2}$ proposed that there is a negative and significant impact of recognition on turnover intentions. The given results do not support $\mathrm{H}_{2}$. There is a very weak andinsignificant relationship between recognition and turnover intentions. It shows that impact of recognition on turnover intentions has a very weak or no effect. It is found that recognition when increases turnover intentions decreases $(\mathrm{r}=-0.1)$ but results showed that recognition is not the strongest factor behind turnover intentions as significance is $\mathrm{p}=0.29$, where ' $\mathrm{p}$ ' must be less than 0.05 .It can be interpreted from the results that there are other more factors behind turnover intentions that have been given more priority by teachers for leaving the universities other than recognition. It shows that for retaining teachers,along with appropriate rewards and recognition, there should also be other beneficial packages for faculty members as components in the creation of successful universities.

Supervisory support is negatively and significantly correlated with turnover intentions. $\mathrm{H}_{3}$ proposed that there is a significant and negative impact of supervisory support on turnover intentions. This prediction is supported. There is a negative and significant relationship between supervisory support and turnover intentions $(\mathrm{r}=-0.21, \mathrm{p}=0.02)$. This supports previous findings that workers wish to leave an organization when they have conflicts with their supervisors or colleagues [22]. Results from the present research suggest that when supervisory support increases turnover intentions of teachers decreases. This significant relationship shows that teachers start thinking of leaving the institution when they don't receive supportive supervision.

Work life policies are significantly and negatively correlated with turnover intentions. $\mathrm{H}_{4}$ proposed that there is a negative and significant impact of work life policies on turnover intentions. This prediction is 
supported. A significant relationship was found between work life policies and turnover intentions $(\mathrm{r}=-0.41$, $\mathrm{p}=0.00)$. This supports previous findings suggesting that Firms, who seek to increase employee morale, commitment and satisfaction, and reduce sources of stress and problems at work, will improve their ability to recruit and retain talented and valued employees [1].Results from the present study suggest that if organizational practices can help employees integrate work and life demands and in turn lower their voluntary turnover rates, then employer's investment in work-life balance practices is more cost- justified.

\subsection{Regression Analysis}

We have Econometric Model as follows:

$\mathrm{TI}=\mathrm{f}(\mathrm{RM}$, REC, $\mathrm{SS}, \mathrm{WLP})$

We may estimate this model in linear form, that is: $\mathrm{TI}=\beta_{0}+\beta_{1} \mathrm{RM}+\beta_{2} \mathrm{REC}+\beta_{3} \mathrm{SS}+\beta_{4} \mathrm{WLP}+\mathrm{e}_{\mathrm{i}}(1)$

Table 2: Regression Analysis Results

\begin{tabular}{|l|l|l|l|}
\hline Independent Variables & Beta $(\beta)$ & t- value & p- value \\
\hline REC & -0.107 & -0.84 & 0.398 \\
\hline WLP & -0.362 & -3.40 & $0.001^{* * *}$ \\
\hline RM & -0.317 & -2.32 & $0.022^{* *}$ \\
\hline SS & -0.321 & -2.15 & $0.034^{* * *}$ \\
\hline
\end{tabular}

$p<0.05^{* *}, N=110$

Dependent Variable $=$ Turnover Intentions

Model $F=10.22 \quad$ Significance $F=0.000$

$R^{2}=0.33$

After having regression analysis results, we can estimate the above linear model (1):

$\mathrm{TI}=5.344-0.317-0.107-0.321-0.362$

(10.156) (-2.32) (-0.84) (-2.15) (-3.40) (t- statistics)

(0.000) (0.022) (0.398) (0.034) (0.001) (p- value/sig. level)

$\mathrm{R}=0.574 \quad \mathrm{R}^{2}=0.33 \quad \mathrm{~F}=10.22(\mathrm{p}$ - value $=0.000) \quad \mathrm{N}=110$

According to the results attained from the linear regression analysis as shown in Table 2, the model is found statistically significant $(\mathrm{F}=10.22, \mathrm{p}<0.01)$; though all the explanatory variables included in the model seem to have explained around $33 \%$ variance in the dependent variable $\left(R^{2}=0.33\right)$. Variable Recognition (REC) appears to be highly statistically insignificant $(\mathrm{p}=0.398)$, compared to variables Remuneration $(\mathrm{RM})$, Supervisory Support (SS) and Work life policies (WLP) with highly statistically significant contribution (p < 0.05). Results suggest that variables RM, SS and WLP negatively contribute towards turnover intentions of faculty members while REC does not contribute. The $t$ value represents the significant impact of independent variables on dependent variable. Value of recognition shows the result that is $t=-0.84$ ( $t$ value must be greater than 2), which represents that recognition has no impact on turnover intentions. It means that teachers tend to think of leaving universities due to some other reasons. And recognition is not the prior reason of quitting for them. The reason for insignificant impact of recognition might be negligence of almost all universities' administrations in case of providing extra rewards and recognition for hard workers, so teachers may think that there is no competition at all in market regarding extra rewards. However, work life policies has highest and strongest impact that is $36 \%$, remuneration also predicts turnover intentions $(\mathrm{t}=-2.32$ and $\mathrm{p}=0.022)$, supervisory support also shows significant impact on turnover intentions that is $(\mathrm{t}=-2.15$ and $\mathrm{p}=0.034)$.

\section{Conclusion}

- This paper gives insight about factors of job satisfaction and their effect on turnover intentions of university teachers of Pakistan. After doing this research, it is being concluded that faculty consider remuneration, supervisory support and work life policies as important factors behind turnover intentions than recognition and rewards.

- Heavy work load and less flexibility at work disturb family life, so teachers prefer those universities where there is a balance in work-life policies.

- It is important to give competitive pay to faculty members.

- Supervisors' leadership skills, communication skills and full support are required for retaining competent teachers.

- Frequent faculty development programs arranged by universities' administrations in order to keep the faculty motivated always increase their trust in the institution administration as a caretaker and supporter.

- Compensation packages, work life policies and supervisory support can be used effectively by university administrators to reduce turnover intentions. 


\section{Recommendations}

- Universities' management should give competitive rewards to good performers to ensure that the culture within the institution promotes hard work and academic achievements. By such effort, recognition can also become as considerable factor of job satisfaction for faculty members which can contribute towards their turnover intentions.

- Every institution should carry out yearly surveys of its turnover rate and explore why faculty members left their jobs. Comparison of the current turnover rate can be made with that of the previous year's rate to check whether the measures taken previously have been successful or not.

- It is recommended for future research to expand the study to a larger group of faculty members, by including universities of other cities.

- Develop a survey that can measure the job satisfaction of faculty members considering moderating and intervening variables (i.e. it assesses job satisfaction in terms of student body, training of faculty members, changes in policies for higher education etc.).

\section{Limitations Of The Study}

- Geographical limitations.

- Other antecedents.

- The study is exclusive of any intervening or moderating variables such as training, new opportunities arising suddenly, changes in administration etc.

- The accuracy of the results may be influenced by biases caused due to lack of trust in confidentiality or other biases. Respondents may hesitate to give the correct information.

\section{References}

[1] P. Cappelli, A Market-Driven Approach to Retaining Talent,Harvard Business Review, 78(1), 2000, $103-111$

[2] P. Drucker, Management for the 21st century (New York: Harper Collins, 1999).

[3] A. Bluedorn, A unified model of turnover from organizations, Journal of Human Relations, 35(2), 1982, $135-153$.

[4] W. Mobley, Intermediate linkages in the relationship between job satisfaction and employee turnover, Journal of Applied Psychology, 62, 1977, 237-240.

[5] M. Valle, K. Harris and M. Andrews, An Examination of Tenure in Negative Organizational Environments, Journal of Management Research, 4(2), 2004, 114-119.

[6] T. Lee and T. Mitchell, An alternative approach: The unfolding model of voluntary employee turnover, Academy of Management Review, 19 (1), 1994, 51-89.

[7] P. Muchinsky and P. Morrow, A multidisciplinary model of voluntary employee turnover, Journal of Vocational Behavior, 14, 1980, 43-47.

[8] P. Spector, Measurement of human service staff satisfaction: development of the job satisfaction survey, American journal of community psychology, 13(6), 1985, 693-713.

[9] A. Chughtai and S. Zafar, Antecedents and consequences of organizational commitment among Pakistani university teachers, Applied HRM Research, 11(1), 2006, 39-64.

[10] N. Khatri and C. Fern, Explaining employee turnover in an Asian context, Human Resource Management Journal, 11(1), 2001, 5474.

[11] K. Carley, Organizational Learning and Personnel Turnover, Organization Science Journal, 3(1), 1992, $20-46$.

[12] E. Naumann, A Conceptual Model of Expatriate Turnover, Journal of International Business Studies, 23(4), $2007,499-531$.

[13] A. Kraut, Predicting turnover of employees from measured job attributes, Organizational Behavior and Human Performance, 13, $1975,233-243$.

[14] T. Huang, J. Lawler and C. YiLei, The Effects of Quality of Work Life on Commitment and Turnover Intention, Journal of Social Behavior and Personality, 35(6), 2007, 735-750.

[15] H. Koh and C. Goh, An analysis of factors affecting the turnover intention of non-managerial clerical staff: a Singapore study, The International Journal of Human Resource Management, 6(1), 1995, 104-125.

[16] J. March and H. Simon, Organizations (New York: Wiley, 1958).

[17] E. Jackofsky and L. Peters, Job turnover versus company turnover: Reassessment of the March and Simon participation hypothesis, Journal of Applied Psychology, 68, 1983, 490-495.

[18] P. Stevens, The job satisfaction of English academics and their intentions to quit academe, doctoral diss., National Institute of Economics and Social Research, 2005.

[19] N. Gans and Y. Zhou, Managing Learning and Turnover in Employee Staffing, Journal of Operations Research, 50(6), 2002, 9911006 .

[20] L. Goodwin, The academic world and the business world: A comparison of occupational goal, Sociology of Education, 42, 1969, $170-187$.

[21] W. Hill and W. French, Perceptions of power of Department of Chairmen by professors, Administrative Science Quarterly, 11, 1967, 548-574.

[22] M. Houkes, Specific relationships between work characteristics and intrinsic work motivation, burnout and turnover intention: A multi-sample analysis, European Journal of work and Organizational Psychology, 10(1), 2001, 1-23. 